\title{
Evaluation and Compare Chairside Time and Accuracy of Indirect Bonding of Orthodontic Attachments Using Double Versus Single Transfer Tray (Split Mouth Design): A Randomized Controlled Trial
}

\section{Mohamed Essam Mohamed ${ }^{1 *}$, Fatma Abdou Abd El Sayed ${ }^{2}$, Hoda Mohamed Abdul Aziz ${ }^{2}$ and Mai Hamdy Aboul Fotouh ${ }^{3}$}

${ }^{1}$ Master Degree, Orthodontic Department, Faculty of Dentistry, Cairo University, Egypt

${ }^{2}$ Professor of Orthodontics, Orthodontic Department, Faculty of Dentistry, Cairo

University, Egypt

${ }^{3}$ Associate Professor of Orthodontics, Orthodontic Department, Faculty of Dentistry, Cairo University, Egypt

*Corresponding Author: Mohamed Essam Mohamed, Master Degree, Orthodontic Department, Faculty of Dentistry, Cairo University, Egypt.
Received: March 31, 2021

Published: April 30, 2021

(C) All rights are reserved by Mohamed Essam Mohamed., et al.

\section{Abstract}

Aim: Comparing the difference between two types of indirect bonding trays (single sheet versus double sheets) regarding chairside time and accuracy of transferring orthodontic attachments in all 3 planes of space using 3D scanning and superimposition.

Methodology: A randomized controlled trial (split mouth design) compared between the single versus double transfer trays techniques was performed, 6 patients with fully erupted full set of permanent teeth were recruited in this study. 84 attachments were bonded to the maxillary teeth from central to second molar for both groups. After placement of the attachments on the working model using water soluble glue regarding the vertical and horizontal reference lines, the model was sprayed with titanium dioxide powder then scanned with intraoral scanner and preoperative STL file was saved. The single and double transfer trays were fabricated, one on each half of the working model then the trays were divided, trimmed and prepared for bonding procedure. The attachments were transferred to the patient's dentition using the two techniques, then the patient's dentition with attachments were scanned with the same intraoral scanner and post- transfer STL file was saved. The chairside time for each group was measured using stopwatch. By using the Geomagic qualify version 12, the two STL files were superimposed and the deviations were detected for 7 values, 4 linear measurements (total linear, mesio-distal, occluso-gingival and bucco-lingual) and 3 angular measurements (tip, torque and rotation). The attachments failure rates were recorded immediately. A visual analog scale was given to each subject to measure their satisfaction towards the both used indirect bonding techniques.

Results: For group I (Single Layer) and group II (Double Layer), mean of chair side time were (8) and (7.235) minutes respectively. For total linear movements, it was revealed that group II was significantly more accurate than group I as P-value was $<0.05$. For tip difference, it was revealed that group II was significantly more accurate than group I as P-value was $<0.05$. For torque difference, it was revealed that group II was significantly more accurate than group I as P-value was $<0.05$. For rotational difference, it was revealed that group II was more accurate than group I without significant difference as P-value was $>0.05$. Total percentages of brackets and tubes failure for group I were $10 \%$ for brackets and $16.66 \%$ for tubes, while for group II were 3.33\% for brackets and $11.11 \%$ for tubes. For group I and group II, mean of patient satisfaction scale were (6.5) and (9) respectively.

Citation: Mohamed Essam Mohamed., et al. "Evaluation and Compare Chairside Time and Accuracy of Indirect Bonding of Orthodontic Attachments Using Double Versus Single Transfer Tray (Split Mouth Design): A Randomized Controlled Trial". Acta Scientific Dental Sciences 5.5 (2021): $140-158$. 
Evaluation and Compare Chairside Time and Accuracy of Indirect Bonding of Orthodontic Attachments Using Double Versus Single Transfer Tray (Split Mouth Design): A Randomized Controlled Trial

Conclusion: Chairside time were comparable between the two indirect bonding techniques using single versus double transfer trays. Attachment's deviations were within the acceptable range of deviation S $0.5 \mathrm{~mm}$ in all 3 planes for both techniques. Double transfer tray found to be superior and more accurate than single transfer tray in all 3 planes for almost all teeth. Attachment failure was more for single transfer tray than double transfer tray, however the difference was not statistically significant. Patient satisfaction was significantly better regarding double transfer tray than single transfer tray as confirmed by results of VAS.

Keywords: Chairside Time; Orthodontic Attachments; Double Versus Single Transfer Tray; Split Mouth Design

\section{Introduction}

Reducing treatment duration is one of the main orthodontist's and patient's concern. However, a variety of new treatment modalities aimed to reduce treatment duration through accelerating tooth movement, yet precise bracket positioning is the most critical and effective controlling factor in treatment duration.

The accurate bracket positioning is an important factor in the efficient application of orthodontic biomechanics and utilizing the full potential of a preadjusted edgewise appliance. So, it's possible to increase predictability of results and reduce the period of finishing stage.

The precise brackets positioning leads to decrease the need for repositioning and finishing bends at the finishing stage therefore shortening the whole treatment time affecting patients satisfaction significantly.

Bracket positioning can be either by direct bonding or indirect bonding. The problems encountered with direct bonding whether light cured or chemically cured include prolonged chair side time, less patient comfort as well as difficulty in bracket positioning in posterior segment and on mal-aligned teeth due to poor access.

Indirect bonding technique allows better 3-dimensional visualization and greater accuracy while positioning brackets since the procedure is carried out in the laboratory, followed by transferring the attachments to the patient's mouth by means of custom-made trays [1], therefore minimizing the errors associated with bracket positioning under any of 3 aspects of observation: height, mesiodistal position and angulation [2]. Moreover, help in decrease plaque accumulation [3] due to decrease resin remnant on the teeth [4].

In order to achieve the desired accuracy in the placement of the orthodontic attachments, the position of these attachments on the casts should be accurately transferred to the patient's teeth. There are factors affecting the accuracy of transfer either related to the tray used for transfer or related to the process of transfer itself.

Since the era of indirect bonding has been widely introduced, there were modifications in the techniques of application regarding bonding system applied, the transfer tray used, preparations of the bracket base and number of transfer trays used.

The main goal of these modifications in method of transfer of brackets was to ensure the accurate transferring of the brackets from the working model to the patient's mouth and decrease the bond failure rate with indirect bonding technique.

The indirect bonding using single tray faced many difficulties such as lack of rigidity, poor adaptation on proper position on teeth surfaces as well as poor stability during curing which necessitate presence of assistant (4 hand technique) [5].

Since there is limited evidence in the literature regarding the accuracy of indirect orthodontic attachments transfer using double transfer trays. Therefore, it was the main aim of this research to conduct a clinical study to evaluate the chair side time and compare the accuracy of transferring orthodontic attachments using new double trays technique with traditional method of transferring which depend on single tray, using 3-dimensional scanning and superimposition of the attachments position. In addition, evaluating the primary bond failure of orthodontic attachments and compare patients satisfaction degree between both techniques.

\section{Materials and Methods}

Randomized Clinical Trial (split mouth design) was performed in this study. Six patients were enrolled in this study having 84 attachments (14 attachments for every patient) in maxillary arch where the two quadrants were randomly divided into two groups. 
Only patients with full set of permanent teeth including the permanent maxillary second molars, with mild to moderate crowding and with good oral hygiene were considered eligible to participate in this trial.

Patients with partially erupted teeth in the maxillary arch, Signs of caries, large restorations, abnormalities of crown morphology, hypo plastic teeth, need of banding, bad oral hygiene measures and severe crowding are considered not eligible for this study. Both treatments were randomly assigned either to the left or right quadrant.

Accurate alginate impression for the upper arch was made in order to make working model for the indirect bonding. Then impression was poured using type- IV extra-hard stone.

Using the $0.03-\mathrm{mm}$ black lead pencil, vertical lines were drawn on the cast from the right to left second molars (Figure 1). Using the same pencil, horizontal lines were drawn on the model on molars and bicuspids connecting buccally the mesial and distal marginal ridges, while for the canines this line connected the ends of cusp slopes.

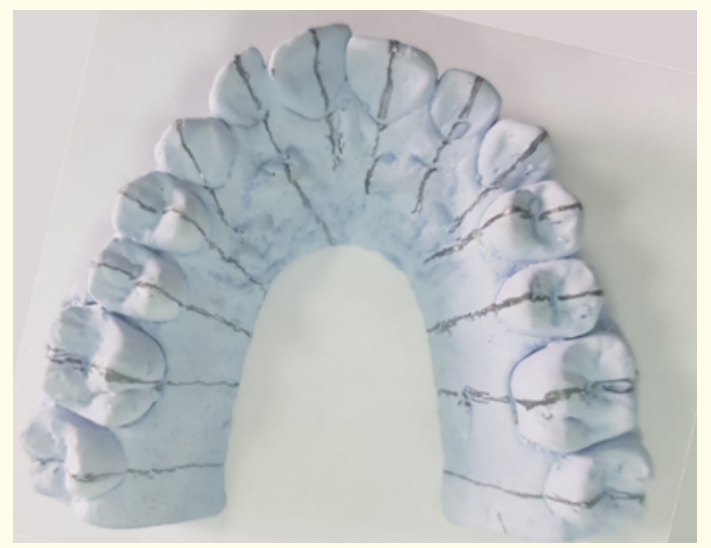

Figure 1

Second horizontal line was drawn buccally using another color lead pencil at the buccal pit of the first molar of one side gingival and parallel to the first line. Using bow divider, distance between the first and second lines was measured and replicated to all teeth (Figure 2).

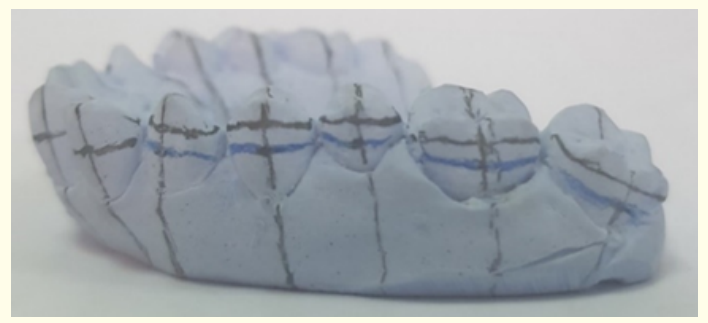

Figure 2

The selected $0.018 \times 0.025$-inch Roth prescription brackets and tubes set were placed on the model with water soluble glue as adhesive (Figure 3) using the drawn vertical and horizontal lines as references for placement. The working cast with attachments was sprayed with a standard layer of titanium dioxide powder coating. Then the sprayed cast was 3D scanned using Cerec CAD/CAM intraoral scanner to capture the first 3D attachments' relation to the working model. The scanned first stereolithographic (STL) file was saved from the scanner software and considered a preoperative STL file (Figure 4).

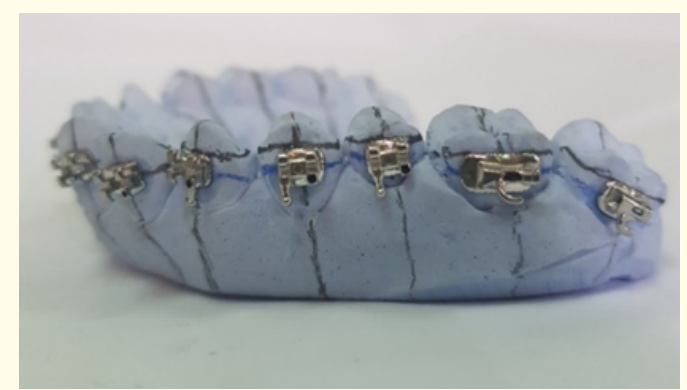

Figure 3

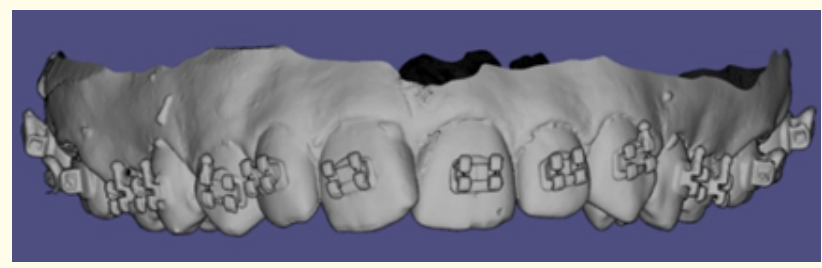

Figure 4 
The cast was divided into two halves, one was control side and the other was intervention side. To fabricate the transfer tray on the first half of the working model, the $1 \mathrm{~mm}$ thickness soft sheet was vacuum formed onto the model and after that soft tray removed with the attachments. One the other side the first tray was fabricated similar to control group then after the tray has been cooled, separating medium was applied on the tray and repeat the process with another hard sheet thick ness $1 \mathrm{~mm}$ over the soft sheet for second tray fabrication (Figure 5). Both trays were removed with the attachments, then were finished using disc to the level of gingival margin and the excess material was trimmed away (Figure 6).

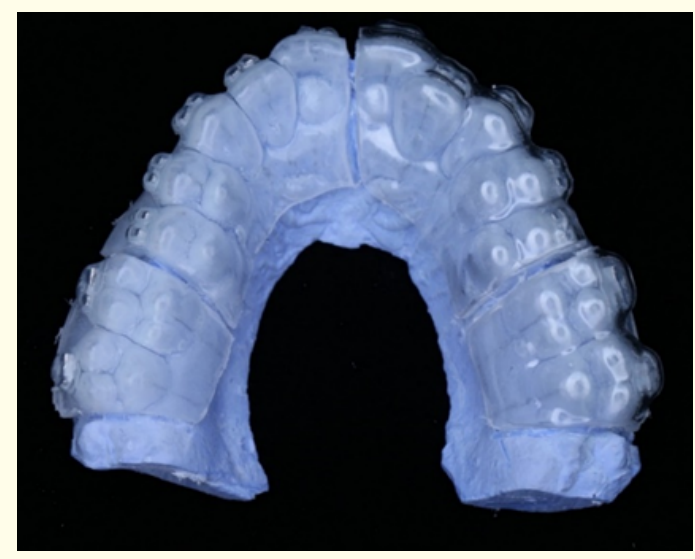

Figure 5

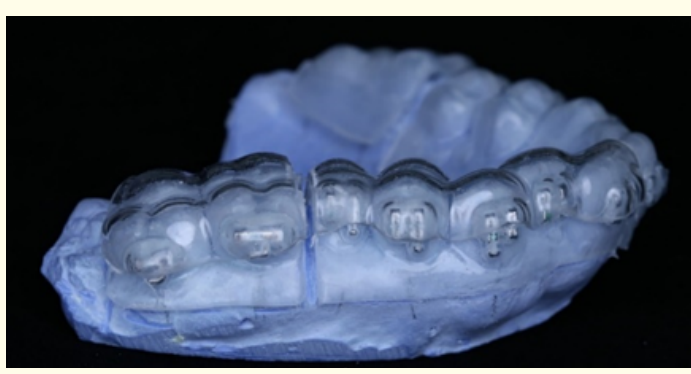

Figure 6

The trays were then cleaned with distilled water and a clean toothbrush then dried with forced air. Then Nola Dry Field System was used for retraction and isolation of working field (Figure 7). Using stopwatch, the chairside time calculation for first group started. The teeth were etched using a 37\% phosphoric acid gel for 14 seconds, then rinsed and gently dried until they had a chalky white appearance. Using a micro brush, a drop of bonding agent was added over the etched surfaces of $1^{\text {st }}$ and $2^{\text {nd }}$ molars. Light cured composite was used to bond the attachments to the enamel surface. A thin composite layer was applied over the attachments base of $1^{\text {st }}$ and $2^{\text {nd }}$ molars and painted with thin layer of bond. The soft tray was quickly inserted in place. Using a hand-held fast light cure device, tray was cured for 30 seconds for every attachment with a firm and steady digits pressure applied over all attachments with help of assistant ( 4 hand technique) for ensuring that all attachments base was firmly attached to its tooth surface in their proper position (Figure 8). Then the tray was removed. Then the same steps were repeated for the other part of tray from central incisor to the $2^{\text {nd }}$ premolar. Stop the time calculation and recorded it in minutes.

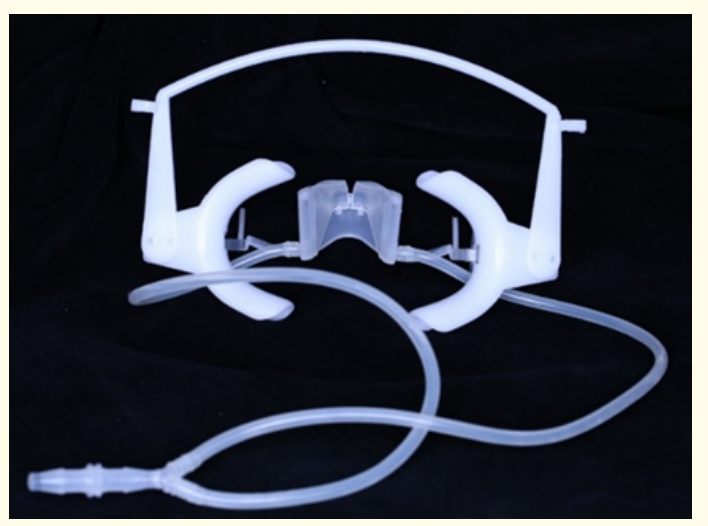

Figure 7

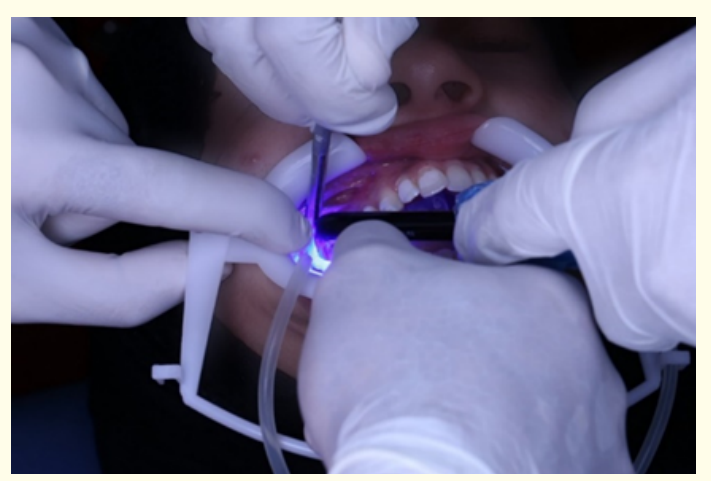

Figure 8 
Time calculation was started again for the second group. The previous steps of control group were repeated. The soft tray was quickly inserted in place followed by insertion of hard tray over it supporting attachments in their proper position (Figure 9). Using a hand-held fast light cure device, tray was cured for 30 seconds for every attachment with ensuring that the hard tray was properly seated in place supporting attachments base firmly attached to its tooth surface. Then the hard tray was removed followed by soft tray. Then previous steps of control group were repeated.

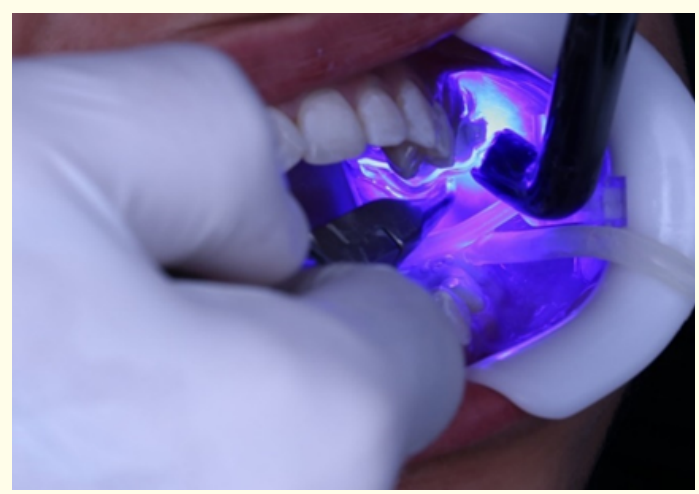

Figure 9

The number of primary failed attachments in each group was recorded. After bonding the attachments on the patient's teeth, they were rinsed including the attachments and dried with gentle air. The oral field was isolated and sprayed with human compatible harmless titanium dioxide powder coating on the teeth and attachments surface (Figure 10). The teeth with the attachments were 3D scanned with the same Cerec CAD/CAM intraoral scanner (Figure 11). The scanned second stereolithographic (STL) file was saved and considered a post-transfer STL file (Figure 12).

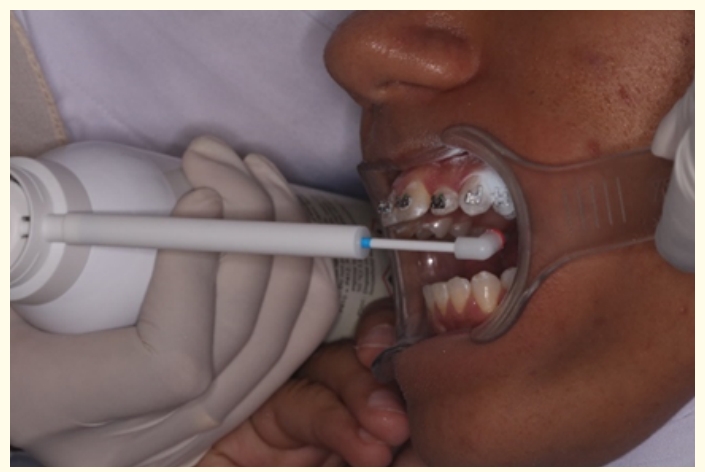

Figure 10

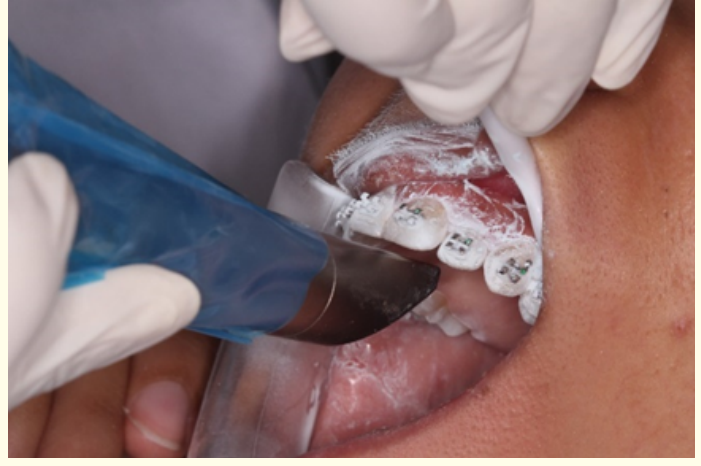

Figure 11

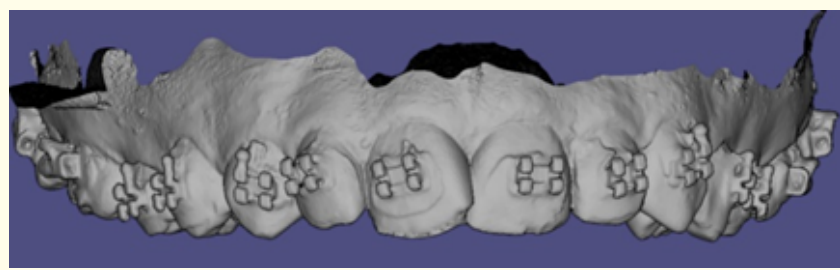

Figure 12

The secondary outcome was to compare the accuracy of orthodontic attachments transfer in all 3 planes of space between the two indirect bonding techniques using 3D scanning and superimposition (Geomagic software).

Wire 12 NiTi was inserted in place and ligated with oties. The failed attachments were recorded in each side separately to calculate the bond failure in each group. Each patient was handled a VAS (visual analog scale) scaled from 0 to 10 where 0 means not satisfied and 10 means the most satisfaction that could be obtained and the patient was instructed to assess each quadrant alone (Figure 13).

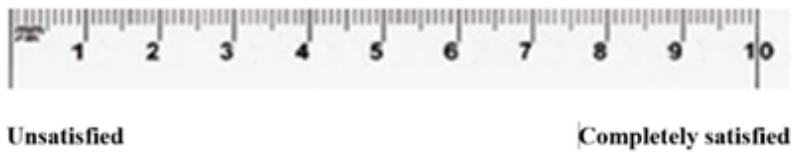

Figure 13

Citation: Mohamed Essam Mohamed., et al. "Evaluation and Compare Chairside Time and Accuracy of Indirect Bonding of Orthodontic Attachments Using Double Versus Single Transfer Tray (Split Mouth Design): A Randomized Controlled Trial". Acta Scientific Dental Sciences 5.5 (2021): 140-158. 
Evaluation and Compare Chairside Time and Accuracy of Indirect Bonding of Orthodontic Attachments Using Double Versus Single Transfer Tray (Split Mouth Design): A Randomized Controlled Trial

Statistical analysis

Statistical analysis was performed with SPSS $20^{\circledR}$, Graph Pad Prism ${ }^{\circledR}$ and Microsoft Excel 2016.

Qualitative data were presented as counts and percentages. Quantitative Data were presented as means and standard deviation (SD) values.

Regarding qualitative data, comparison was performed using Chi square test. On the other hand, quantitative data were explored for normality by using Shapiro Wilk Normality test and then independent $t$ test were performed for parametric data.

\section{Results}

Regarding chair side time of group I (Single Layer) and group II (Double Layer), mean and standard deviation were calculated for each tooth.

For group I and group II, mean of chair side time were (8) and (7.235) minutes respectively, as listed in table 1. Performing independent $t$ test between both groups, it was revealed that there was insignificant difference between both groups as P-value was $>0.05$, as listed in table 1.

Regarding the total linear movements of the attachments of group I (Single Layer) and group II (Double Layer) which means

\begin{tabular}{|c|c|c|c|c|c|c|}
\hline & \multirow[t]{3}{*}{$\mathbf{N}$} & \multicolumn{4}{|c|}{ Group } & \multirow[t]{3}{*}{ P-value } \\
\hline & & \multicolumn{2}{|c|}{$\begin{array}{c}\text { Group I } \\
\text { (Single Layer) }\end{array}$} & \multicolumn{2}{|c|}{$\begin{array}{c}\text { Group II (Double } \\
\text { Layer) }\end{array}$} & \\
\hline & & $\begin{array}{c}M \\
\text { (min.) }\end{array}$ & SD & $\begin{array}{c}M \\
\text { (min.) }\end{array}$ & SD & \\
\hline $\begin{array}{c}\text { Chair Side } \\
\text { Time }\end{array}$ & 6 & 8 & 1.614 & 7.235 & 1.281 & 0.3845 \\
\hline
\end{tabular}

Table 1: min: minute, N: Patients Count, M: Mean, SD: Standard Deviation, P: Probability Level.

the linear movement of attachments in 3-dimension plans, mean and standard deviation were calculated for each tooth in microns. Then mean difference was performed to detect the level of significance between both groups.

The double layer trays showed significantly more accurate attachments transfer than the single layer tray in the following teeth (upper canine, first premolar, second premolar and first molar), while there was no significant difference in the attachments transfer measurements between both groups in the following teeth (upper lateral and second molar), while the single layer tray was significantly more accurate in (upper central) only as listed in table 2.

For overall teeth, it was revealed that group II (double layer) was significantly more accurate than group I (single layer) as Pvalue was $<0.05$, as listed in table 2 .

\begin{tabular}{|c|c|c|c|c|c|c|c|}
\hline \multirow{3}{*}{$\begin{array}{l}\text { Tooth } \\
\text { No. }\end{array}$} & \multirow[t]{3}{*}{$\mathbf{N}$} & \multicolumn{4}{|c|}{ Group } & \multirow{3}{*}{$\begin{array}{l}\text { Mean difference } \\
\text { (microns) }\end{array}$} & \multirow[t]{3}{*}{ P-value } \\
\hline & & \multicolumn{2}{|c|}{ Group I (Single Layer) } & \multicolumn{2}{|c|}{ Group II (Double Layer) } & & \\
\hline & & M (microns) & SD & M (microns) & SD & & \\
\hline 1 & 6 & 100 & 32.62 & 252 & 82.21 & -151 & $0.0018^{*}$ \\
\hline 2 & 6 & 244 & 79.60 & 232 & 75.68 & 12 & 0.7944 \\
\hline 3 & 6 & 321 & 104.71 & 57 & 18.59 & 264 & $0.0001^{*}$ \\
\hline 4 & 6 & 361 & 117.76 & 151 & 49.26 & 210 & $0.0024^{*}$ \\
\hline 5 & 6 & 392 & 127.87 & 150 & 48.93 & 242 & $0.0015^{*}$ \\
\hline 6 & 6 & 656 & 213.99 & 428 & 123.31 & 278 & $0.0461^{*}$ \\
\hline 7 & 6 & 479 & 156.26 & 327 & 106.67 & 152 & 0.0774 \\
\hline \multicolumn{2}{|c|}{ Overall } & 364.71 & 118.97 & 228.00 & 72.09 & 143.7 & 0.0299* \\
\hline
\end{tabular}

Table 2: Tooth No: tooth number, N: Attachments Count, M: Mean, SD: Standard Deviation, P: Probability Level.

*: Significant difference P-value $\leq 0.05$. 
Evaluation and Compare Chairside Time and Accuracy of Indirect Bonding of Orthodontic Attachments Using Double Versus Single Transfer Tray (Split Mouth Design): A Randomized Controlled Trial

Regarding mesio-distal deviation (X-axis) of group I (Single Layer) and group II (Double Layer), mean and standard deviation were calculated for each tooth in microns. Then mean difference was performed to detect the level of significance between both groups.

The double layer trays showed significantly more accurate attachments transfer than the single layer tray in the following teeth (upper lateral, canine, first premolar, second premolar and second molar), while there was no significant difference in the attachments transfer measurements between both groups in (upper first molar), while the single layer tray was significantly more accurate in (upper central) only as listed in table 3.

For overall teeth, it was revealed that group II (double layer) was significantly more accurate than group I (single layer) as Pvalue was $<0.05$, as listed in table 3 .

\begin{tabular}{|c|c|c|c|c|c|c|c|}
\hline \multirow{3}{*}{$\begin{array}{c}\text { Tooth } \\
\text { No. }\end{array}$} & \multirow[t]{3}{*}{$\mathbf{N}$} & \multicolumn{4}{|c|}{ Group } & \multirow{3}{*}{$\begin{array}{l}\text { Mean difference } \\
\text { (microns) }\end{array}$} & \multirow[t]{3}{*}{ P-value } \\
\hline & & \multicolumn{2}{|c|}{ Group I (Single Layer) } & \multicolumn{2}{|c|}{ Group II (Double Layer) } & & \\
\hline & & M (microns) & SD & M (microns) & SD & & \\
\hline 1 & 6 & 59 & 19.25 & 107 & 34.90 & -48 & $0.0145^{*}$ \\
\hline 2 & 6 & 160 & 52.19 & 53 & 17.29 & 107 & $0.0008^{*}$ \\
\hline 3 & 6 & 222 & 72.42 & 25 & 8.16 & 197 & $0.0001^{*}$ \\
\hline 4 & 6 & 236 & 76.99 & 73 & 23.81 & 163 & $0.0006^{*}$ \\
\hline 5 & 6 & 272.5 & 56.43 & 89 & 29.03 & 183.5 & $0.0088^{*}$ \\
\hline 6 & 6 & 428 & 139.62 & 281.5 & 93.30 & 146.5 & 0.0651 \\
\hline 7 & 6 & 375 & 122.33 & 41 & 13.37 & 334 & $0.0001^{*}$ \\
\hline \multicolumn{2}{|c|}{ Overall } & 250.35 & 77.03 & 95.67 & 31.41 & 139.85 & 0.0040 * \\
\hline
\end{tabular}

Table 3: Tooth No: tooth number, N: Attachments Count, M: Mean, SD: Standard Deviation, P: Probability Level. *: Significant difference P-value $\leq 0.05$

Regarding occluso-gingival deviation (Z-axis) of group I (Single Layer) and group II (Double Layer), mean and standard deviation were calculated for each tooth in microns. Then mean difference was performed to detect the level of significance between both groups.

The double layer trays showed significantly more accurate attachments transfer than the single layer tray in the following teeth (upper canine, first premolar, second premolar and first molar), while there was no significant difference in the attachments transfer measurements between both groups in (upper second molar), while the single layer tray was significantly more accurate in the following teeth (upper central and lateral) as listed in table 4.

For overall teeth, it was revealed that group II (double layer) was significantly more accurate than group I (single layer) as Pvalue was $<0.05$, as listed in table 4 .

\begin{tabular}{|c|c|c|c|c|c|c|c|}
\hline \multirow{3}{*}{$\begin{array}{l}\text { Tooth } \\
\text { No. }\end{array}$} & \multirow[t]{3}{*}{$\mathbf{N}$} & \multicolumn{4}{|c|}{ Group } & \multirow{3}{*}{$\begin{array}{l}\text { Mean difference } \\
\text { (microns) }\end{array}$} & \multirow[t]{3}{*}{ P-value } \\
\hline & & \multicolumn{2}{|c|}{ Group I (Single Layer) } & \multicolumn{2}{|c|}{ Group II (Double Layer) } & & \\
\hline & & M (microns) & SD & M (microns) & SD & & \\
\hline 1 & 6 & 65 & 21.20 & 160 & 52.19 & -95 & $0.002^{*}$ \\
\hline 2 & 6 & 34 & 11.09 & 224 & 40.45 & -190 & $0.0001^{*}$ \\
\hline 3 & 6 & 59 & 19.25 & 12 & 7.91 & 47 & $0.0003^{*}$ \\
\hline 4 & 6 & 219 & 71.44 & 50 & 16.31 & 167 & $0.0002^{*}$ \\
\hline 5 & 6 & 260 & 84.82 & 99 & 32.29 & 161 & $0.0015^{*}$ \\
\hline 6 & 6 & 381 & 124.29 & 76 & 24.79 & 305 & $0.0002^{*}$ \\
\hline 7 & 6 & 183 & 76.01 & 206 & 67.20 & -23 & 0.589 \\
\hline \multicolumn{2}{|c|}{ Overall } & 177.57 & 58.30 & 118.14 & 34.45 & 74.9 & $0.0291^{*}$ \\
\hline
\end{tabular}

Table 4: Tooth No: tooth number, N: Attachments Count, M: Mean, SD: Standard Deviation, P: Probability Level. *: Significant difference P-value $\leq 0.05$. 
Evaluation and Compare Chairside Time and Accuracy of Indirect Bonding of Orthodontic Attachments Using Double Versus Single Transfer Tray (Split Mouth Design): A Randomized Controlled Trial

Regarding bucco-lingual deviation (Y-axis) of group I (Single Layer) and group II (Double Layer), mean and standard deviation were calculated for each tooth in microns. Then mean difference was performed to detect the level of significance between both groups.

The double layer trays showed significantly more accurate attachments transfer than the single layer tray in the following teeth (upper lateral and canine), while there was no significant difference in the attachments transfer measurements between both groups in the following teeth (upper first premolar, second premolar, first molar and second molar), while the single layer tray was significantly more accurate in (upper central) only as listed in table 5.

For overall teeth, it was revealed that group II (double layer) was more accurate than group I (single layer) without significant difference as P-value was $>0.05$, as listed in table 5 .

\begin{tabular}{|c|c|c|c|c|c|c|c|}
\hline \multirow{3}{*}{$\begin{array}{l}\text { Tooth } \\
\text { No. }\end{array}$} & \multirow[t]{3}{*}{$\mathbf{N}$} & \multicolumn{4}{|c|}{ Group } & \multirow{3}{*}{$\begin{array}{l}\text { Mean difference } \\
\text { (microns) }\end{array}$} & \multirow[t]{3}{*}{ P-value } \\
\hline & & \multicolumn{2}{|c|}{ Group I (Single Layer) } & \multicolumn{2}{|c|}{ Group II (Double Layer) } & & \\
\hline & & M (microns) & SD & M (microns) & SD & & \\
\hline 1 & 6 & 47 & 15.33 & 82 & 26.75 & -35 & $0.0194 *$ \\
\hline 2 & 6 & 154 & 50.24 & 12 & 3.91 & 142 & $0.0001^{*}$ \\
\hline 3 & 6 & 130 & 42.41 & 49 & 15.98 & 81 & $0.0014^{*}$ \\
\hline 4 & 6 & 105 & 34.25 & 147 & 47.95 & -42 & 0.1114 \\
\hline 5 & 6 & 97 & 31.64 & 63 & 20.55 & 34 & 0.0518 \\
\hline 6 & 6 & 213 & 69.48 & 190 & 61.98 & 23 & 0.5586 \\
\hline 7 & 6 & 189 & 61.65 & 239 & 77.96 & -50 & 0.246 \\
\hline \multicolumn{2}{|c|}{ Overall } & 133.57 & 43.57 & 111.71 & 36.44 & 21.8 & 0.3596 \\
\hline
\end{tabular}

Table 5: Tooth No: tooth number, N: Attachments Count, M: Mean, SD: Standard Deviation, P: Probability level.

*: Significant difference P-value $\leq 0.05$.

Regarding tip difference of group I (Single Layer) and group II (Double Layer), mean and standard deviation were calculated for each tooth in degrees. Then mean difference was performed to detect the level of significance between both groups.

The double layer trays showed significantly more accurate attachments transfer than the single layer tray in the following teeth (upper lateral, first premolar and first molar), while there was no significant difference in the attachments transfer measurements between both groups in the following teeth (upper central, canine and second molar), while the single layer tray was significantly more accurate in (upper second premolar) only as listed in table 6 .

For overall teeth, it was revealed that group II (double layer) was significantly more accurate than group I (single layer) as Pvalue was $<0.05$, as showed in table 6 .

\begin{tabular}{|c|c|c|c|c|c|c|c|}
\hline \multirow{3}{*}{$\begin{array}{c}\text { Tooth } \\
\text { No. }\end{array}$} & \multirow[t]{3}{*}{$\mathbf{N}$} & \multicolumn{4}{|c|}{ Group } & \multirow{3}{*}{$\begin{array}{c}\text { Mean difference } \\
\text { (degrees) }\end{array}$} & \multirow[t]{3}{*}{ P-value } \\
\hline & & \multicolumn{2}{|c|}{ Group I (Single Layer) } & \multicolumn{2}{|c|}{ Group II (Double Layer) } & & \\
\hline & & M (degrees) & SD & M (degrees) & SD & & \\
\hline 1 & 6 & 1.4 & 0.46 & 1.52 & 0.50 & -0.1 & 0.6745 \\
\hline 2 & 6 & 0.86 & 0.28 & 0.48 & 0.16 & 0.42 & $0.0162^{*}$ \\
\hline 3 & 6 & 1.59 & 0.52 & 2.19 & 0.71 & -0.6 & 0.1259 \\
\hline 4 & 6 & 1.9 & 0.62 & 0.18 & 0.06 & 1.72 & $0.0001^{*}$ \\
\hline 5 & 6 & 1.25 & 0.41 & 2.21 & 0.72 & -0.95 & $0.0176^{*}$ \\
\hline 6 & 6 & 5.27 & 1.72 & 0.95 & 0.31 & 4.32 & $0.0001^{*}$ \\
\hline 7 & 6 & 2.55 & 0.83 & 1.73 & 0.56 & 0.82 & 0.0726 \\
\hline \multicolumn{2}{|c|}{ Overall } & 2.12 & 0.69 & 1.32 & 0.43 & 0.8 & $0.021^{*}$ \\
\hline
\end{tabular}

Table 6: Tooth No: tooth number, N: Attachments Count, M: Mean, SD: Standard Deviation, P: Probability Level. *: Significant difference P-value $\leq 0.05$. 
Evaluation and Compare Chairside Time and Accuracy of Indirect Bonding of Orthodontic Attachments Using Double Versus Single Transfer Tray (Split Mouth Design): A Randomized Controlled Trial

Regarding torque difference of group I (Single Layer) and group II (Double Layer), mean and standard deviation were calculated for each tooth in degrees. Then mean difference was performed to detect the level of significance between both groups.

The double layer trays showed significantly more accurate attachments transfer than the single layer tray in the following teeth (upper central, lateral, second premolar and first molar), while there was no significant difference in the attachments transfer measurements between both groups in the following teeth (upper canine, first premolar and second molar) as listed in table 7.

For overall teeth, it was revealed that group II (double layer) was significantly more accurate than group I (single layer) as Pvalue was $<0.05$, as listed in table 7 .

\begin{tabular}{|c|c|c|c|c|c|c|c|}
\hline \multirow{3}{*}{$\begin{array}{l}\text { Tooth } \\
\text { No. }\end{array}$} & \multirow[t]{3}{*}{$\mathbf{N}$} & \multicolumn{4}{|c|}{ Group } & \multirow{3}{*}{$\begin{array}{l}\text { Mean difference } \\
\text { (degrees) }\end{array}$} & \multirow[t]{3}{*}{ P-value } \\
\hline & & \multicolumn{2}{|c|}{ Group I (Single Layer) } & \multicolumn{2}{|c|}{ Group II (Double Layer) } & & \\
\hline & & M (degrees) & SD & M (degrees) & SD & & \\
\hline 1 & 6 & 1.79 & 0.58 & 0.18 & 0.06 & 1.6 & $0.0001^{*}$ \\
\hline 2 & 6 & 1.98 & 0.65 & 0.88 & 0.29 & 1.1 & $0.003^{*}$ \\
\hline 3 & 6 & 2.76 & 0.90 & 2.56 & 0.84 & 0.2 & 0.699 \\
\hline 4 & 6 & 3.27 & 1.07 & 3.80 & 1.24 & -0.6 & 0.4464 \\
\hline 5 & 6 & 3.02 & 0.99 & 1.09 & 0.36 & 1.93 & $0.0005^{*}$ \\
\hline 6 & 6 & 4.27 & 1.39 & 2.72 & 0.89 & 1.5 & $0.0442^{*}$ \\
\hline 7 & 6 & 3.42 & 1.12 & 2.41 & 0.79 & 1.01 & 0.1012 \\
\hline \multicolumn{2}{|c|}{ Overall } & 2.93 & 0.96 & 1.95 & 0.64 & 0.98 & $0.047^{*}$ \\
\hline
\end{tabular}

Table 7: Tooth No: tooth number, N: Attachments Count, M: Mean, SD: Standard Deviation, P: Probability Level. *: Significant difference P-value $\leq 0.05$

Regarding rotational difference of group I (Single Layer) and group II (Double Layer), mean and standard deviation were calculated for each tooth in degrees. Then mean difference was performed to detect the level of significance between both groups.

The double layer trays showed significantly more accurate attachments transfer than the single layer tray in the following teeth (upper central, canine, first premolar and second premolar), while there was no significant difference in the attachments transfer measurements between both groups in the following teeth (upper lateral and second molar), while the single layer tray was significantly more accurate in (upper first molar) only as listed in table 8.

For overall teeth, it was revealed that group II (double layer) was more accurate than group I (single layer) without significant difference as P-value was $>0.05$, as listed in table 8.

\begin{tabular}{|c|c|c|c|c|c|c|c|}
\hline \multirow{3}{*}{$\begin{array}{l}\text { Tooth } \\
\text { No. }\end{array}$} & \multirow[t]{3}{*}{$\mathbf{N}$} & \multicolumn{4}{|c|}{ Group } & \multirow{3}{*}{$\begin{array}{c}\text { Mean difference } \\
\text { (degrees) }\end{array}$} & \multirow[t]{3}{*}{ P-value } \\
\hline & & \multicolumn{2}{|c|}{ Group I (Single Layer) } & \multicolumn{2}{|c|}{ Group II (Double Layer) } & & \\
\hline & & M (degrees) & SD & M (degrees) & SD & & \\
\hline 1 & 6 & 2.01 & 0.66 & 1.24 & 0.40 & 1.6 & $0.0346^{*}$ \\
\hline 2 & 6 & 1.41 & 0.46 & 1.05 & 0.34 & 0.35 & 0.1542 \\
\hline 3 & 6 & 3.90 & 1.27 & 1.48 & 0.48 & 2.5 & $0.0014^{*}$ \\
\hline 4 & 6 & 2.74 & 0.89 & 1.21 & 0.39 & 1.5 & $0.003^{*}$ \\
\hline 5 & 6 & 2.41 & 0.79 & 0.87 & 0.28 & 1.6 & $0.0011^{*}$ \\
\hline 6 & 6 & 1.93 & 0.63 & 4.21 & 1.37 & -2.2 & $0.0041^{*}$ \\
\hline 7 & 6 & 2.07 & 0.68 & 1.47 & 0.48 & 0.6 & 0.1079 \\
\hline \multicolumn{2}{|c|}{ Overall } & 2.35 & 0.77 & 1.65 & 0.53 & 0.7 & 0.891 \\
\hline
\end{tabular}

Table 8: Tooth No: tooth number, N: Attachments Count, M: Mean, SD: Standard Deviation, P: Probability Level.

$*$ : Significant difference P-value $\leq 0.05$. 
Evaluation and Compare Chairside Time and Accuracy of Indirect Bonding of Orthodontic Attachments Using Double Versus Single Transfer Tray (Split Mouth Design): A Randomized Controlled Trial

Regarding no. of immediate attachment failure of group I (Single Layer) and group II (Double Layer), total attachment failure were counted for each bracket and tube for each group.

For group I, there were 3 brackets and 3 tubes failed, as listed in table 9. While for group II, there were 1 bracket and 2 tubes failed, as listed in table 9.

Total percentages of brackets and tubes failure for group I were $10 \%$ for brackets and $16.66 \%$ for tubes, while for group II were $3.33 \%$ for brackets and $11.11 \%$ for tubes, as listed in table 9 .

\begin{tabular}{|c|c|c|c|c|c|}
\hline \multirow{2}{*}{} & \multicolumn{4}{|c|}{ Group } & \multirow{2}{*}{$\begin{array}{c}\text { P- } \\
\text { value }\end{array}$} \\
\cline { 2 - 5 } & $\begin{array}{c}\text { Group I (Single } \\
\text { Layer) }\end{array}$ & $\begin{array}{c}\text { Group II (Double } \\
\text { Layer) }\end{array}$ & \\
\cline { 2 - 5 } & $\begin{array}{c}\text { Brackets } \\
\text { (N) }\end{array}$ & $\begin{array}{c}\text { Tubes } \\
\text { (N) }\end{array}$ & $\begin{array}{c}\text { Brackets } \\
\text { (N) }\end{array}$ & $\begin{array}{c}\text { Tubes } \\
\text { (N) }\end{array}$ & \\
\hline $\begin{array}{c}\text { Attach- } \\
\text { ment } \\
\text { Failure }\end{array}$ & 3 & 3 & 1 & 2 & \multirow{2}{*}{0.476} \\
\hline Total & 30 & 18 & 30 & 18 & \\
\hline $\begin{array}{c}\text { Failure } \\
\%\end{array}$ & $10 \%$ & $16.66 \%$ & $3.33 \%$ & $11.11 \%$ & \\
\hline
\end{tabular}

Table 9: N: attachments count, \%; Percentage, P: Probability Level.

Regarding patient satisfaction evaluated by VAS of group I (Single Layer) and group II (Double Layer), mean and standard deviation were calculated for each group on scale out of (10).

\begin{tabular}{|c|c|c|c|c|c|c|}
\hline \multirow{2}{*}{} & \multirow{2}{*}{$\mathbf{N}$} & \multicolumn{4}{|c|}{ Group } & \multirow{2}{*}{ P-value } \\
\cline { 2 - 5 } & & \multicolumn{2}{|c|}{$\begin{array}{c}\text { Group I } \\
\text { (Single Layer) }\end{array}$} & \multicolumn{2}{c|}{$\begin{array}{c}\text { Group II } \\
\text { (Double Layer) }\end{array}$} & \\
\cline { 2 - 5 } & & $\begin{array}{c}\text { M } \\
\text { (grade) }\end{array}$ & SD & M & SD & \\
(grade) & & \\
\hline $\begin{array}{c}\text { Patient } \\
\text { Satisfaction } \\
\text { Scale }\end{array}$ & 6 & 6.5 & 1.6 & 9 & 2.3 & $0.0437^{*}$ \\
\hline
\end{tabular}

Table 10: N: Patients Count, M: Mean, SD: Standard Deviation, P: Probability Level.
For group I and group II, mean of patient satisfaction scale were (6.5) and (9) respectively, as listed in table 10.

\section{Discussion}

The main goals of inducing the Indirect bonding in orthodontics were improving the accuracy of attachment placement, increasing patient`s satisfaction through decreasing discomfort during bonding and saving the chairside time [6]. As Silverman and Cohen stated [7], it should take no longer than twenty minutes to complete bonding of both arches, including the second molars if desired.

The more accurate attachment placement early in treatment the less need for later repositioning or complex wire bending later at the finishing stage [8] thus improving efficiency of treatment and shortening treatment time which will reduce the complications accompanying orthodontic treatment e.g. white spot lesions and root resorption [9]. Aiming to achieve the advantages of indirect bonding different techniques for indirect bonding were introduced [10].

Although several studies compared the direct versus indirect bonding [11] and different indirect bonding techniques [12], yet there were not enough studies in the literature which compared indirect bonding using single vs double transfer trays. Moreover the available studies ignored patient's satisfaction regarding chairside time and comfort, in addition to bond failure rate which was evaluated only by Castilla., et al. [13] directly after tray removal only. Furthermore the methods used for testing accuracy between the two techniques lack reliability [14] and validity as they used CBCT [15] or photographs [16] for measurements.

Thus, the aim of the present study was to compare chairside time, accuracy of attachments transfer and bond failure between two different indirect bonding techniques which may affect patient's satisfaction.

Regarding the sample used, the study included maxillary teeth only to avoid any confounding factors attributed to the difficulty of isolating the mandibular dentition, also with fully erupted first and second permanent molars in the maxilla, in addition to mild to moderate crowding to facilitate the indirect bonding trays placement in the patient's mouth. 
Evaluation and Compare Chairside Time and Accuracy of Indirect Bonding of Orthodontic Attachments Using Double Versus Single Transfer Tray (Split Mouth Design): A Randomized Controlled Trial

Furthermore, teeth to be bonded shouldn't have signs of caries, large restorations, fluorosis, hypoplasia or abnormalities of crown morphology that would affect the bonding quality and the failure rate. Good oral hygiene and no signs of gingival inflammation were important criteria, if there was inflammation within the gingival area that would be covered by the indirect bonding tray, isolation and keeping a dry field would be almost impossible which will definitely affect the bond strength. Patients with treatment plan requiring bands were excluded because the study was on accuracy of transfer of bonded attachments only.

As for the study design, split mouth design was chosen to avoid inter-subject variability from the estimated treatment effect and potentially requires fewer subjects than a parallel-group trial with the same power. The split mouth design that was used in randomization to distribute the sample, was to decide the order in which quadrants were bonded in order to avoid the selection bias that may have arisen from using the same technique first in every subject and to balance the groups with respect to many known and unknown confounding factors.

Concerning the preclinical preparation full dentition scaling and polishing were done to remove dental calculus and plaque and to ensure a healthy periodontium with no bleeding upon bonding brackets which affect bonding quality and increase failure rate significantly. Furthermore, the patients were instructed to maintain this condition by oral hygiene measures. Any chipped areas were smoothened to ensure proper attachments placement in place with standard position and ultimate accuracy according to proper measurements from incisal edges and cusp tips.

A single-operator protocol of the laboratory (primary impressions, pouring, bonding to the working models, trays fabrication) and clinical bonding procedures were applied to reduce variabilities if multi-operator protocol was used in contrast to Grünheid., et al. [17] where a multi operator protocol was used.

The primary impression was poured using type-IV extra-hard stone to avoid fracture of the weak parts of the cast as incisal edges and cusp tips while removing the cast from the impression and to reduce the possibility of decay and scratches of the cast during handling until scanning time. The trimming of the poured cast in the form of $U$ shape removing the palatal part was done to facilitate the suction of sheet by vacuum machine on the cast.
As for the working cast preparation for attachments bonding, in respect to the reference lines for attachments positioning the vertical and horizontal reference lines were drawn on the model as described by Nojima., et al. [18] for attachments placement. The vertical reference line was extended buccally and palatally on the cast to ensure bonding the bracket according to the long axes of teeth, to help in simulating root direction and accordingly help in proper angulation of attachment which mainly follows the root direction for proper roots parallelism. The vertical lines were drawn from palatal to buccal direction to allow for maximum accuracy upon drawing the line along the long axis.

For better finishing the first horizontal line was drawn in respect to the marginal ridges not the cusp tips, because proper leveling of teeth are related to marginal ridges itself while the cusp tips may have variation in length and sharpness. Furthermore, the ABO grading criteria for leveling and alignment depends on the marginal ridge levels of teeth. The two horizontal lines were first drawn on the $1^{\text {st }}$ permanent molar because it is the most important key of occlusion.

The distance between the marginal ridge of first permanent molar and the buccal pit was measured with a bow divider and duplicated to the premolars, $2^{\text {nd }}$ permanent molars and canines. The bow divider aided in duplication of the $2^{\text {nd }}$ horizontal line properly to the rest of maxillary dentition.

The vertical and horizontal reference lines on the cast were the guidance for the desired position (mesiodistally and occlusogingivally) and angulation (tip and rotation) of the attachments while adhering the attachment to the cast were done by water soluble glue with gentle pressure on attachment was required to squeeze the excess glue and allow proper positioning.

The orthodontic attachments used in this study were American orthodontics Roth prescription slot 0.022 inch because there was a digital library for these attachments was used later in the superimposition procedure by Geomagic software.

Water soluble glue adhesive used to fix attachments on the model because of its water solubility it could be washed away with water providing a virgin meshwork, plus it's thin enough to allow maximum adaptation of the attachment to the working model. The attachments were left on the working model for at least 5 minutes 
Evaluation and Compare Chairside Time and Accuracy of Indirect Bonding of Orthodontic Attachments Using Double Versus Single Transfer Tray (Split Mouth Design): A Randomized Controlled Trial

in order to allow for complete setting of the glue in, to avoid any movement of the bracket during tray fabrication. The retention of the attachments was checked with sharp explorer to ensure the attachment retention. Excess glue was removed all around the attachments with explorer to ensure maximum adaptation of the tray on the working model.

In respect to working cast preparation for scanning, The working cast with attachments was sprayed with titanium dioxide powder coating to avoid metallic reflection of the metal attachments which may affect precision of digital scanning leading to areas of attachments not scanned well and therefore affect the measurements of accuracy [14]. The sprayed cast with attachments was scanned using Cerec Omnicam CAD/CAM intraoral scanner to stabilize the same scanner machine for preoperative and post-transfer scanning and to eliminate any variation between the two scanned STL files.

In this study a comparison between single and double vacuum formed transfer trays was used. The vacuum formed trays was chosen because it is the most common tray used [14], the most comfortable tray for the patient, transparent so allows for composite light curing throw it and can be used for rebonding the failed attachments. The single vacuum sheet tray was used as a comparator method for indirect bonding as it was checked for accuracy in many studies [13] while the double vacuum sheets tray was chosen to be examined for its ease of use and stability and rigidity during bonding procedure so it could be advisable for use among orthodontists. The soft tray was $1 \mathrm{~mm}$ thickness to avoid attachments retention to the thicker sheet and avoid instability of thinner sheet. The use of the second hard tray in the intervention group was with the aim of increasing the stability of the soft tray in proper position and eliminate the need for assistant.

Concerning transfer trays preparation the margins of the second tray (hard sheet) were trimmed to the level that cover most of the occlusal and the incisal parts of the attachment without reaching the gingival undercut to facilitate removal of the tray after bonding, because the hard tray was rigid and stiff [14]. The trimming of the soft tray $1 \mathrm{~mm}$ apical to the gingival margin was to allow for precise trays installment in its proper position.

The trays were divided into two halves to make two groups of two different techniques intervention and control groups. As shorten the segment of tray as the isolation was better, so both sides of the trays were divided into two parts. The first part from central incisor to the $2^{\text {nd }}$ premolar and the second for $1^{\text {st }}$ and $2^{\text {nd }}$ molars only. This division was to allow for proper isolation especially in case of posterior part, proper support of tray during bonding and feasibility of tray detachment after bonding without the risk of attachment failure. Interdental vertical cuts in the soft tray were done to facilitate disengagement of the hooks and wings of the attachments and avoid debonding while removing the tray.

As for attachments bonding preparations a 50 um aluminum oxide powder micro etcher and toothbrush were used for the attachments bases cleaning to efficiently clean the surface of the base from any residual stone, glue or separating medium refreshing surface to prepare it for bonding, in addition to its positive effect on the shear bond strength of the base as described by Larry White [19].

The patient's teeth were polished using fluoride-free pumice paste then cleaned with $5.25 \%$ sodium hypochlorite solution to remove any plaque biofilm which may affect bonding strength of the attachments and may lead to its failure.

For the control group (single tray) firm and steady digits pressure applied over all attachments with help of assistant (4 hand technique) for ensuring that all attachments bases were firmly attached to its teeth surfaces in their proper position. The removal of soft sheet after bonding procedure was done from palatal to buccal for easier release of attachments without hanging on the hooks and wings of the attachments with the help of the buccal interdental vertical cuts. On the other side (double trays) the second hard sheet was supporting the attachments bases in their proper position in close contact with the teeth surfaces without need for assistant helping in digits pressure over the attachments (no need for 4 hands technique). The failed attachments were rebonded again separately with same technique using their separated specific part of tray for rebonding.

Concerning preparation for intraoral scanning after attachments bonding the oral field was isolated and sprayed with human compatible harmless titanium dioxide powder coating on the teeth and attachments surface to improve the accuracy of scanning, to avoid metallic reflection of metal attachments and to eliminate the powder layer thickness difference between the preoperative and the post-transfer scans. 
Evaluation and Compare Chairside Time and Accuracy of Indirect Bonding of Orthodontic Attachments Using Double Versus Single Transfer Tray (Split Mouth Design): A Randomized Controlled Trial

The preoperative and the post-transfer scans were done using Cerec Omnicam CAD/CAM intraoral scanner due to its high precision in scanning as described by Patzelt., et al [20].

Regarding the primary outcome which was to measure the chair side time for each technique, as patient satisfaction is one crucial aspect to be considered. Thus, reducing the chair side time would definitely be more comfortable for the patient. Patient`s satisfaction was obtained by visual analog scale assessment which signifies the more comfortable technique for the patient that assumed less chairside time as it was responsive and easy-to-use tool for evaluating treatment satisfaction [21].

In relation to the secondary outcome which was to measure the bond failure of orthodontic attachments immediately after detachment of transfer tray, wire insertion and ligation between the two techniques to observe which technique has better bonding quality. A follow up period for the secondary outcome was ignored to avoid any confounding factors such as masticatory forces and patients might prefer biting on one side rather than the other one etc.

With regard to the tertiary outcome which was to compare the accuracy of orthodontic attachment transfer in all 3 planes of space between the two indirect bonding technique using 3D scanning and superimposition. The super imposition between the pre and post scans showed the discrepancy the two scans in the form of two different colors (zebra pattern). To ensure that any deviation detected by the software was an actual deviation in position of the bonded attachment and was not due to decay in the scanned material or differences during the scanning procedure itself, an ideal virtual attachment for each tooth from the digital library was used as a model in the preoperative and post-transfer models. The scans were first manually traced, to allow for maximum registration between the ideal virtual attachment and the scans attachment.

Geomagic Qualify 12 software was used to evaluate the positional deviation between the 3D surface scanned preoperative and postoperative models. The first 3D surface scanned preoperative model was set as a reference, and the 3D surface scanned postoperative model was set as test, the superimposition area included the attachments and the models themselves [22].

This current study used a new method to check accuracy that was described by El Nigoumi based on the reliability of 3D models in terms of linear and volumetric measurements [23]. The usage of digital scanning has many benefits, 1) the benefit of using digitally acquired 3D surface data which allow for precise and repeatable measurements unlike 2D photography images that was used previously, 2) capturing very minute sharp details up to parts of microns, because of the high accuracy of the intra oral scanning, and the avoidance of metal artifacts during the scanning procedure, 3) eliminating the need of subjecting the patient to any kind of unnecessary radiation when using other modalities like CBCT.

The coordinate system of the model was adjusted so that the $\mathrm{X}$ axis represented the mesio-distal direction, the $\mathrm{Y}$ axis represented the bucco-lingual direction, and the occluso-gingival direction was represented by the $\mathrm{Z}$ axis, thus, when a deviation was recorded on the $\mathrm{X}$ axis for example, it was representing a mesio-distal deviation, and so on.

For the linear deviation measurements -vertical, mesio-distal and in and out movements- a point at the center of gravity of the ideal virtual attachment was detected by the software as a coordinate system and defined as "centroid', deviations along the $\mathrm{X}, \mathrm{Y}$, $\mathrm{Z}$ axes were recorded at this point. The reason why the linear deviations were measured at this point was that it's known from a biomechanical point of view that the center of gravity of an object would be the least point to be affected by the rotational movements if the object was rotating around this point, thus, any deviation at any axis would be the result of a bodily movement on this axis and not due to rotation.

When interpreting the data acquired in this study, it was important to note that any deviation for example in the tube position refers to the positioning of the tube itself. For example, a value of $0.10 \mathrm{~mm}$ on the $\mathrm{X}$ plane would reflect that the tube was bonded $0.10 \mathrm{~mm}$ to the mesial than was originally intended based on the working model.

For the angular deviation the ideal virtual attachment supported by 4 cubes one on each wing of the attachment to allow for accurate angular (tip, torque and rotation) measurements between the pre and post scans. After manual tracing, the automated registration of the ideal virtual attachment provided two templates, a scanned model template and intraoral scan template. Super imposition of both templates would give us the opportunity to measure linear discrepancy throw centroid and angular discrepancy throw cubes in all 3 planes. 
Evaluation and Compare Chairside Time and Accuracy of Indirect Bonding of Orthodontic Attachments Using Double Versus Single Transfer Tray (Split Mouth Design): A Randomized Controlled Trial

Concerning chairside time results for single compared to double trays there was insignificant difference between both groups, where the chairside time were 8 minutes and 7.23 minutes for control and intervention groups respectively. The approximate chair side time between the two groups was due to the same steps followed except the need for assistant support in the control group which consumed little more time for curing of each attachment. This results were consistent with the results of Bozelli., et al. [24] in study comparing direct versus indirect bonding, where the chair side time of indirect bonding was 6 minutes. While Yildrim., et al. [10] found the chair side time 26 minute because it was included the full maxillary and mandibular arches for each group.

Superimposition experiments of the present study yielded 7 values for each attachment, reflecting the 3-dimensional linear and angular deviations along the various translational planes and rotational axes. On the contrary Aguirre., et al. [25] used occlusogingival and tip deviation only. Then Koo., et al. [26] used occlusogingival, mesio-distal and tip deviation in photographic superimposition.

Grunheid., et al. [27] recorded the acceptable range of deviation in accuracy $\leq 0.5 \mathrm{~mm}$ linearly and $\leq 2.0^{\circ}$ angularly. These limits were selected as they represent professional standards: During case evaluation using the American Board of Orthodontics objective grading system, points are subtracted for teeth that deviate 0.5 $\mathrm{mm}$ or more from proper alignment in the categories "alignment" and "marginal ridges. A crown-tip inadequacy of $2^{\circ}$ causes a marginal ridge discrepancy of $0.5 \mathrm{~mm}$ in an average-sized molar.

Regarding accuracy of transfer of the single and double vacuumformed transfer trays, when the accuracy of both trays were compared, both trays showed a mean linear deviation within $-0.5:+0.5$ $\mathrm{mm}$ which was the acceptable range. While regarding the angular deviation in the 3 planes the double trays group showed a mean within $-2^{\circ}:+2^{\circ}$ which was the acceptable range, on the other hand the single tray showed slight changes away from this range reaching $2.93^{\circ}$ in the torque.

Concerning the linear deviations, the total linear movement of the attachments in the 3 planes of space showed significant better accuracy for intervention group with overall deviation $0.22 \mathrm{~mm}$ compared to $0.36 \mathrm{~mm}$ for control group. The total linear movement deviation of each attachment of control group was up to $0.65 \mathrm{~mm}$ while the intervention group up to $0.42 \mathrm{~mm}$. therefore, it can be concluded that the total linear movement of the attachments from the reference desired position on the teeth was significantly better in the intervention group with double vacuum-formed trays.

With regard to the results of linear mesio-distal discrepancy showed that the mean deviation of the control group was up to 0.42 $\mathrm{mm}$ while intervention group up to $0.28 \mathrm{~mm}$. The overall mean deviation was 0.25 and $0.09 \mathrm{~mm}$ for control and intervention groups respectively which showed significant difference in accuracy of transfer with superiority for the double vacuum-formed trays due to the pressure exerted by operator in the control group for support which may not be perpendicular on the teeth. This values was close to results of Koo., et al. [26] with mesio-distal deviation 0.18 $\mathrm{mm}$. The authors found that the mesiodistal measurements were small for all samples. This may be due to the smaller surface area measured from a two-dimensional picture than the actual value measured on a 3-dimensional curved tooth surface. In the present study the mesio-distal movement was noticed to be more distal in the single tray which explained by force applied by the operator and assistant digits as support for attachments in proper contact with teeth which directed posteriorly in distal direction as it was difficult to apply perpendicular pressure on the attachments.

Regarding the occluso-gingival deviation the discrepancy in control group was up to $0.38 \mathrm{~mm}$ while in intervention group up to $0.22 \mathrm{~mm}$ with significant improve in accuracy with using double vacuum-formed trays. Since the overall deviation of double trays $0.118 \mathrm{~mm}$ compared to $0.17 \mathrm{~mm}$ for single tray which means significant better precision of transfer.

The overall deviation was less in comparison with that of Koo., et al. [26] which was $0.31 \mathrm{~mm}$ as they used Boon gauge for measuring the height in their study. A major drawback of using this device was that the Boon gauge can be tilted and thus yields different height results.

On the other side Hodge., et al. [28] found that Occluso-gingival deviation more than mesio-distal more than angular this may have occurred because tooth crowns are generally less wide than they are long and there may be less scope for bracket positioning errors.

In the present study the better transfer accuracy of double trays were seen in all teeth except the $1^{\text {st }}$ and $2^{\text {nd }}$ incisors which showed 
Evaluation and Compare Chairside Time and Accuracy of Indirect Bonding of Orthodontic Attachments Using Double Versus Single Transfer Tray (Split Mouth Design): A Randomized Controlled Trial

significantly less accuracy of transfer, a finding which may be explained as the $1^{\text {st }}$ and $2^{\text {nd }}$ incisors were more accessible to the operator for good digits support without any vibration with the single tray, while with the double tray some pressure exerted on the attachments that was not equalized from opposite side because these attachments were on the end of tray.

The assumption was that most vertical positioning errors should be biased towards the occlusal because incompletely seating of the indirect transfer tray was seemingly more likely than over-seating of tray during the clinical bonding procedure. But in the present study there was not any significant difference in direction of occluso-gingival deviation in both groups. But Lee [29] stated that the direction was more gingival (60\%), this errors could possibly imply that the indirect transfer trays may be "stretched" during the clinical bonding procedure by the operator's fingers pressing the tray gingivally. Stretching of the transfer tray could also occur if the tray's occlusal coverage was not adequate enough to prevent over seating or the tray stretched and "rolled" facially and gingivally under finger pressure.

On the other hand, the bucco-lingual deviation showed insignificant difference in overall teeth between the two groups. Since the overall deviations were $0.13 \mathrm{~mm}$ and $0.11 \mathrm{~mm}$ for control and intervention groups respectively. Furthermore, no significant difference in the bucco-lingual deviation regarding separate teeth except $2^{\text {nd }}$ incisors and canine which showed superiority of double trays and $1^{\text {st }}$ incisor which showed superiority of the single tray. The deviation in the control group was up to $0.21 \mathrm{~mm}$ and in the intervention group up to $0.23 \mathrm{~mm}$. It was expected that due to additional adhesive being applied to the brackets and teeth during the clinical bonding procedure, there was a bucco-lingual bias towards the buccal. The opposite happened the most move lingually specially in single tray group which explained by the uncontrolled pressure applied by the operator as support which may cause more squeezing for the tray and the attachments decreasing the thickness of composite than the thickness of glue on the cast. This leads to more lingual position of the attachments in comparison to the primary position on the cast. This over pressure can't be exerted by the double trays because the hard tray applies a proper pressure which allow the attachments for proper contacts with the teeth. This direction was opposite to that of Lee [29] which showed more buccal (79\%).
The superiority of the control group regarding the $1^{\text {st }}$ incisor was due to good accessibility of this tooth which allow for proper pressure and support without vibration. An important notice should be taken in consideration that not all bucco-lingual movements mean change in composite thickness especially some deviations exceeded the all thickness of composite. So, most of buccolingual movements related to the mesio-distal or occluso-gingival movements due to the convex buccal tooth surface which means that any mesial, distal, occlusal or gingival movement will necessarily cause buccal or lingual movement of the attachment.

Concerning the angular deviations, the acceptable range of angular deviation was $\leq 2^{\circ}$ as mentioned by Grunheid., et al. [27]. As for the results of attachments tip showed significant difference between the two groups, since the overall angular deviation of the control group was $2.12^{\circ}$ similar to Koo., et al. [26] with deviation $2.43^{\circ}$ while the intervention group was $1.32^{\circ}$ similar to Aguirre., et al. [14] with tip deviation 1.3 degree. The change in tip in the control group was up to $5.27^{\circ}$ while in the intervention group up to $2.21^{\circ}$. The intervention group was significant more accurate in 3 attachments (lateral, first premolar and first molar) while the control was significant better in 1 attachment (second premolar). There was not any significant difference in the tip direction whether between the two groups or within each group.

Regarding the torque deviation there was significant difference between the two groups, where the overall deviation of single sheet group was $2.93^{\circ}$, while the double sheets group was $1.95^{\circ}$. The deviation of the control group was up to $4.27^{\circ}$ while in the intervention group was up to $3.80^{\circ}$. When consider the separate teeth, the double sheets group showed significant better accuracy in 4 attachments (central, lateral, second premolar and first molar). There was no any significant difference regarding the direction of torque deviation whether positive or negative torque. Researcher should take in consideration that not all change in the torque means change in the regularity of composite layer or change in pressure on the attachments. Since the buccal surface of the tooth is convex, so any occlusal or gingival movement will cause change in attachment`s torque.

The results of rotation showed insignificant difference overall between the two groups. The deviation in the control group was 
Evaluation and Compare Chairside Time and Accuracy of Indirect Bonding of Orthodontic Attachments Using Double Versus Single Transfer Tray (Split Mouth Design): A Randomized Controlled Trial

up to $3.90^{\circ}$ while in the intervention group was up to $4.21^{\circ}$. The direction of rotation was significantly toward mesial out in both groups and this result explained mainly due to convex shape of buccal surface of the tooth with operator pressure during tray insertion which always directed posteriorly pushing the attachment more distal leading to rotation of the attachments mesial out. So, any mesial or distal movement of the attachment will cause deviation of the attachment's rotation.

Furthermore, the largest deviations in this study were noticed at the posterior separation sites of the segmented trays. One might assume that transfer precision correlates with the number of teeth simultaneously fitted with attachments and hence with the tray's span, so that precision would be greatly reduced when using single-tooth trays. Molars were the most directionally biased teeth. A potential explanation for this finding was that it was more difficult to hold indirect transfer trays as precisely and steadily in the molar region than in other areas of the mouth because of decreased access.

The available research that compared single vacuum formed vs double vacuum formed trays was by Castilla., et al. [13] in which they compare 5 different indirect bonding trays regarding the accuracy of transfer using digital photographs. But they measured the linear deviation only. Linear mesio-distal, occluso-gingival by digital photographs and linear bucco-lingual by calipers. In contrast to the present, they found that double vacuum formed trays had the most teeth with significant linear discrepancies. This would be due to their use of silicone trays which were more rigid. Low rigidity in an indirect bonding tray may result not only in inaccurate bracket position transfer, but also in an increased number of bond failures due to poor adaptation. They used different trays thickness than the present study, since the single tray was $1.5 \mathrm{~mm}$ soft while the double trays were $0.75 \mathrm{~mm}$ soft and $1.5 \mathrm{~mm}$ soft without hard tray. The greatest number of significant discrepancies occurred in the occluso-gingival dimension, followed by bucco-lingual and mesiodistal. But a limitation of this study was that it used an ideal dental arch model, rather than the typical clinical scenario of crowded and/or rotated teeth. Different results might be found in arches with irregular tooth alignment, as tray dimensions would vary, and different tray materials may respond differently to the divergent crown angulations.
Although Lee [29] measured 3 linear and 3 angular deviation measurements as the present study, the linear deviation in his study was up to $0.73 \mathrm{~mm}$ and angular was up to $7.32^{\circ}$ which consider high in comparison to the present study because CBCT tracing was used, which was not accurate as 3D scanning tracing in the present study.

The most recent study comparing the accuracy of two indirect bonding techniques was presented by Schmid., et al. [14] which compared the accuracy between silicone and double vacuum formed trays ( $1 \mathrm{~mm}$ soft and $0.75 \mathrm{~mm}$ hard) using intra oral scanner like the present study. Their outcomes were 6 measurements, 3 linear and 3 angular. The biggest error in the linear variables occurred in the occluso-gingival direction, followed by the buccolingual then the mesio-distal directions which was similar result to the present study.

Regarding angular deviation torque showed the biggest error followed by tip and rotation, which also was similar result to the present study. All result values were less than the present study because it was an in-vitro study, which implies that the error may be higher in an in-vivo setting, due to additional factors like initial bracket positioning error or limited accessibility in the mouth with more difficult transfer.

On the other hand, Wendl., et al. [30] measured the accuracy of indirect bonding transfer tray using extra oral scanner. The transfer of the brackets from the plaster to the working model was carried out using the Aptus bonding device. The mean deviations were $0.15 \mathrm{~mm}$ along the $\mathrm{X}$ - axis (mesio-distal), $0.17 \mathrm{~mm}$ along the $\mathrm{Y}$ axis (occluso-gingival), and $0.19 \mathrm{~mm}$ along the $\mathrm{Z}$ - axis (bucco- lingual). The higher discrepancies in comparison to the present study were due to the different indirect transfer technique which used instable device for brackets transfer.

Regarding attachments failure there was insignificant difference between both groups whether the failed brackets or tubes. Although the failure in the intervention group was lower but the difference was statistically insignificant. In control group the failure rate was $10 \%$ and $16.6 \%$ for brackets and tubes respectively. On the other hand, the failure rate in intervention group were $3.3 \%$ and $11.1 \%$ for brackets and tubes respectively. This outcome was affected by several confounding factors as bonding material, tooth 
surface status, degree of isolation and transfer trays. So, the failure rate changed extremely between different studies. Aguirre., et al. [25] found that failure rate of indirect bonding group was $4.1 \%$ which was close result to that found by Read., et al. [31] 6.4\%, Alexander [32] 5.4\%, Menini., et al. [33] 2.77\% and Thiyagarajah., et al. [34] 2.2\%. Other papers showed increase of indirect bonding failure rate due to low bond strength that affected by adhesive, the bonding agent or the method of bracket base treatment as Bozelli., et al. [24] with failure rate 7.1\%, Vijayakumar., et al. [35] 8.8\%, Dixon., et al. [12] 9\%, Lee [29] 9.8\%, Yildirim., et al. [10] 10.7\% and Zachrisson., et al. [36] with failure rate $10 \%$. Only one study showed very low failure rate presented by Schmid., et al. [14] which used double vacuum formed trays as transfer trays with failure rate $0.7 \%$.

The patients satisfaction was significantly better in the intervention group with satisfaction degrees 9 in comparison with 6.5 degrees in the control group. This more satisfaction was due to less chair side time, less pressure on the teeth, more comfort because no need for assistant ( 4 hand technique) and the more presentable steps to the patients.

\section{Conclusion}

1. Chairside time were comparable between the two indirect bonding techniques using single versus double transfer trays.

2. Linear attachments deviations were within the acceptable range of deviation $\leq 0.5 \mathrm{~mm}$ in all 3 planes for both techniques.

3. Double transfer tray found to be superior and more accurate than single transfer tray for linear deviation in all 3 planes for almost all teeth.

4. Both trays were almost similar regarding mesio-distal and occluso-gingival linear directional deviation, however the single transfer tray showed more lingual directional deviation.

5. Double transfer tray found to be superior and more accurate than single transfer tray for tipping, torque and rotation angular deviation for almost all teeth.

6. Both trays were almost similar regarding tipping and torque angular directional deviation, however they both showed rotational mesial out deviation.
7. Finally it could be concluded that double transfer tray was more accurate than single transfer tray for almost overall linear or angular movements for almost all teeth.

8. Attachment failure was more for single transfer tray than double transfer tray, however the difference was not statistically significant.

9. Patient satisfaction was significantly better regarding double transfer tray than single transfer tray as confirmed by results of VAS.

\section{Recommendations}

1. Replace the direct bonding by indirect bonding technique which will help in reducing of errors in attachments positioning and improving the final treatment results, thus decreasing the finishing stage and consequently overall treatment duration.

2. Use the double transfer trays technique which will facilitate the bonding procedure by eliminating the need for assistant (4 hand technique) which is more comfortable for both the patient and orthodontist. In addition to decrease the thickness of soft tray as much as possible to allow its detachment after curing of the orthodontic attachments.

3. Divide the transfer tray into sections and use of isolation control device which will allow for better isolation control, thus decreasing the attachments failure rate.

4. Take the advantage of modern technologies as 3D scanning and 3D printing which will facilitate the indirect bonding technique and increase transfer accuracy with the improvement of scanners precision.

5. Use the digital scanning and digital positioning of the attachments from the virtual library which will decrease the laboratory stage duration and increase the accuracy of positioning.

6. Conduct further studies to compare the chairside time, accuracy of attachments transfer, bond failure and patient's satisfaction between single and double vacuum transfer trays but with different materials and thicknesses. 


\section{Bibliography}

1. Shpack N., et al. "Bracket Placement in Lingual vs Labial Systems and Direct vs Indirect Bonding". The Angle Orthodontist 77.3 (2007): 509-517.

2. Koo B., et al. "Comparison of the accuracy of bracket placement between direct and indirect bonding techniques". American Journal of Orthodontics and Dentofacial Orthopedics 116.3 (1999): 346-351.

3. Dalessandri D., et al. "Effectiveness of an indirect bonding technique in reducing plaque accumulation around braces". The Angle Orthodontist 82.2 (2012): 313-318.

4. Sinha P., et al. "Bond strengths and remnant adhesive resin on debonding for orthodontic bonding techniques". American Journal of Orthodontics and Dentofacial Orthopedics 108.3 (1995): 302-307.

5. Ciuffolo F., et al. "Modified bonding technique for a standardized and effective indirect bonding procedure". American Journal of Orthodontics and Dentofacial Orthopedics 141.4 (2012): 504-509.

6. Aguirre M., et al. "Assessment of bracket placement and bond strength when comparing direct bonding to indirect bonding techniques". American Journal of Orthodontics 82.4 (1982): 269-276.

7. Silverman E., et al. "A universal direct bonding system for both metal and plastic brackets". American Journal of Orthodontics 62.3 (1972): 236-244.

8. McLaughlin R and Bennett J. "Finishing and detailing with a preadjusted appliance system". Journal of Clinical Orthodontics 25.4 (1991): 251-264.

9. Khalaf K. "Factors affecting the formation, severity and location of white spot lesions during orthodontic treatment with fixed appliances". Journal of Oral and Maxillofacial Research 5.1 (2014): 1-10.

10. Ylldırım K and Aydinatay B. "Comparative assessment of treatment efficacy and adverse effects during nonextraction orthodontic treatment of Class I malocclusion patients with direct and indirect bonding: A parallel randomized clinical trial". American Journal of Orthodontics and Dentofacial Orthopedics 154.1 (2018): 26-35.

11. Hocevar $\mathrm{R}$ and Vincent $\mathrm{H}$. "Indirect versus direct bonding: Bond strength and failure location". American Journal of Orthodontics and Dentofacial Orthopedics 94.5 (1988): 367-371.

12. Dixon G. "Comparison of two orthodontic indirect bonding methods". Thesis Submitted to University of Louisville School of Dentistry (2011).

13. Castilla A., et al. "Measurement and comparison of bracket transfer accuracy of five indirect bonding techniques". The Angle Orthodontist 84.4 (2014): 607-614.

14. Schmid J., et al. "Transfer accuracy of two indirect bonding techniques-an in-vitro study with 3D scanned models". The European Journal of Orthodontics 1.1 (2018): 1-7.

15. Grunheid T., et al. "Accuracy, reproducibility, and time ef fi ciency of dental measurements using different technologies". American Journal of Orthodontics and Dentofacial Orthopedics 145.2 (2014): 157-164.

16. Hodge T., et al. "A randomized clinical trial comparing the accuracy of direct versus indirect bracket placement". Journal of Orthodontics 31 (2004): 132-137.

17. Grunheid T., et al. "Transfer accuracy of vinyl polysiloxane trays for indirect bonding". The Angle Orthodontist 86.3 (2016): 468-474.

18. Nojima L., et al. "Indirect orthodontic bonding - a modified technique for improved efficiency and precision". Dental Press Journal of Orthodontics 20.3 (2015): 109-117.

19. White L. "A new and improved indirect bonding technique". Journal of Clinical Orthodontics 33.1 (1999): 17-23.

20. Patzelt S., et al. "Accuracy of full-arch scans using intraoral scanners". Clinical Oral Investigations 18.1 (2014): 1687-1694.

21. Lucas C., et al. "Stability, responsiveness, and reproducibility of a visual analog scale for treatment satisfaction in migraine". The American Headache Society 52.6 (2012): 1005-1018.

Citation: Mohamed Essam Mohamed., et al. "Evaluation and Compare Chairside Time and Accuracy of Indirect Bonding of Orthodontic Attachments Using Double Versus Single Transfer Tray (Split Mouth Design): A Randomized Controlled Trial". Acta Scientific Dental Sciences 5.5 (2021): $140-158$. 
22. Vecsei B., et al. "Comparison of the accuracy of direct and indirect three-dimensional digitizing processes for CAD/CAM systems - An in-vitro study". Journal of Prosthodontic Research 61.2 (2017): 177-184.

23. Nigoumi A. "Assessing the accuracy of indirect bonding with 3D scanning technology". Journal of Clinical Orthodontic 10 (2016): 627-633.

24. Bozelli J., et al. "Comparative study on direct and indirect bracket bonding techniques regarding time length and bracket detachment". Dental Press Journal of Orthodontics 18.6 (2013): 51-57.

25. Aguirre M., et al. "Assessment of bracket placement and bond strength when comparing direct bonding to indirect bonding techniques". American Journal of Orthodontics 82.4 (1982): 269-276.

26. Koo B., et al. "Comparison of the accuracy of bracket placement between direct and indirect bonding techniques". American Journal of Orthodontics and Dentofacial Orthopedics 116.3 (1999): 346-351.

27. Grunheid T., et al. "Transfer accuracy of vinyl polysiloxane trays for indirect bonding". The Angle Orthodontist (2015): 1-7.

28. Hodge T., et al. "A randomized clinical trial comparing the accuracy of direct versus indirect bracket placement". Journal of Orthodontics 31 (2004): 132-137.

29. Lee M. "Indirect bonding of orthodontic brackets: an evaluation of transfer accuracy and reliability". Thesis Submitted to Faculty of dentistry University of Minnesota (2014).

30. Wendl B., et al. "Indirect bonding - a new transfer method". The European Journal of Orthodontics 30.1 (2008): 100-107.

31. Read M and Brien K. "A clinical trial of an indirect bonding technique with a visible light-cured adhesive". American Journal of Orthodontics and Dentofacial Orthopedics 98.3 (1990): 259-262.
32. Cranford A. "Clinical comparison of two indirect bonding systems on retention rates of orthodontic brackets: chemical cured custom base vs light cured non-custom base". Thesis Submitted to Faculty of Dentistry University of Alabama at Birmingham (2009).

33. Menini A., et al. "A 15-month evaluation of bond failures of orthodontic brackets bonded with direct versus indirect bonding technique: a clinical trial". Progress in Orthodontics 15.70 (2014): 1-6.

34. Thiyagarajah S., et al. "A clinical comparison of bracket bond failures in association with direct and indirect bonding". Journal of Orthodontics 33 (2006): 198-204.

35. Vijayakumar R., et al. "How and why of orthodontic bond failures: An in-vivo study". Journal of Pharmacy and Bioallied Sciences 6.1 (2014): 85-90.

36. Zachrisson B and Brobakken B. "Clinical comparison of direct versus indirect bonding with different bracket types and adhesives". American Journal of Orthodontics 74.1 (1978): 62-78.

\section{Assets from publication with us}

- Prompt Acknowledgement after receiving the article

- Thorough Double blinded peer review

- Rapid Publication

- Issue of Publication Certificate

- High visibility of your Published work

Website: www.actascientific.com/

Submit Article: www.actascientific.com/submission.php Email us: editor@actascientific.com

Contact us: +919182824667 